\title{
Léducation par « la lumière de la foi du Prophète » selon le shaykh 'Abd al-'Azīz al-Dabbāgh (m. 1332/1719)
}

D’après le Kitāb al-ibrīz de Aḥmad b. al-Mubārak (m. 1156/1743)

\author{
Jean-Jacques Thibon
}

Au moins jusqu'au V $\mathrm{V}^{\mathrm{e}} / \mathrm{XI}^{\mathrm{e}}$ siècle, les soufis exprimaient leur amour de Dieu de manière directe tandis que leur amour du Prophète était plus discrètement mentionné, à quelques rares exceptions. Ainsi la longue section de la Risāla de Qushayrī (m. 465/1072) sur l'amour (maḩabba) ne parle pas de l'amour du Prophète, mais exclusivement de l'amour de Dieu. Cet amour, chez Sarī al-Saqațī, est tel qu'il ne laisse plus la moindre place à rien d'autre' ${ }^{1}$ Et le contenu des traités de soufisme de même époque, autour des $\mathrm{X}^{\mathrm{e}}$ et $\mathrm{XI}^{\mathrm{e}}$ siècles, suit la même logique. Kharrāz, maître bagdadien mort autour de 280/895, voyant le Prophète en rêve, s'excuse de ne pouvoir lui consacrer plus d'amour tant il est occupé par l'amour de Dieu². À propos de l'épisode célèbre où Abū Bakr, ayant apporté tous ses biens au Prophète, répondit à celui-ci qui lui demandait ce qu'il avait conservé pour sa famille : «Dieu et son Prophète », Abū Bakr al-Wāsițī (m. après 32o /932), disciple de Junayd (m. 297/910) qui partit s'établir à Marv où il finit sa vie, fit le commentaire suivant : « Si ce n'était par pudeur en présence du Prophète, il n'aurait pas dit 'et son prophète' mais aurait mentionné seulement l'Unique $»^{3}$. Formulé de manière plus prosaïque : Dieu seul eût suffi, nul besoin de mentionner son Prophète.

Même dans l'expression des fondements de la voie spirituelle, le rôle du Prophète est somme toute restreint ; il ne lui est du moins accordé aucune centralité. Il suffit pour s'en convaincre de rappeler les propos de Sahl al-Tustarī, l'un des tout premiers à en énoncer les principes. Certes, il place fort logiquement l'imitation de la sunna prophétique, après un attachement sans faille

1 "Le cœur qui contient ces cinq choses ne peut rien abriter d'autre : la crainte de Dieu seul, l'espoir en Dieu seul, l'amour pour Dieu seul, la honte devant Dieu et l'intimité procurée par Lui seul"; Thibon, Les générations, $\mathrm{n}^{\circ} 3 \mathrm{O}, 7 \mathrm{O}$.

2 Qushayrī, al-Risāla, 634 (bābal-maḥabba).

3 Thibon, La voie des Hommes sincères, 27-64, § 13, 39. 
au Livre de Dieu. Mais à la suite de cette référence à la sunna, au demeurant assez vague quant à son contenu, figurent six autres principes, qui tranchent par leur précision et dont il est difficile de dire s'ils sont énoncés par ordre d'importance : manger de la nourriture licite, s'abstenir de nuire, s'écarter des transgressions de la loi, se repentir, s'acquitter des devoirs ${ }^{4}$. On constate que les considérations d'ordre social, ou du moins relevant des relations humaines et de la vie en société occupent une place non négligeable. Dans le même ouvrage, les cinq principes qui, selon Junayd, distinguent son école (ușūlmadhhabinā), ne mentionnent ni le Prophète ni sa sunna ${ }^{5}$. Se plaçant sur un autre plan, mais plus radical dans l'expression, Ja'far al-Șādiq (m. 148/765) n'admet aucun intermédiaire ni la moindre diversion quand il affirme : « La voie spirituelle (tarīq) va du cour à Dieu, en se détournant de tout ce qui est autre que Lui ${ }^{6}$.

Une telle attitude est révélatrice d'une époque où, quand il est question de fana $\bar{a}^{\prime}$, l'extinction, et Kharrāz déjà cité fut l'un des premiers à en parler, il s'agit de l'extinction en Dieu, le fanā’ fi Allāh. Quant au Prophète, il apparaît principalement dans nos sources comme un modèle à suivre. Ainsi Dhū l-Nūn al-Mișrī, (m. 245/86o) affirme : «L'un des signes (qui révèlent) l'amoureux de Dieu, c'est l'imitation (mutāba'a) de l'Aimé de Dieu dans ses vertus (ahlāq), dans ses actes, dans ses prescriptions (awāmir) et dans le détail de sa règle de vie (sunan) ${ }^{7}$. Dans ces premiers siècles, les pratiques ascétiques, veille, jeûne et silence, représentent pour beaucoup de spirituels mentionnés dans les manuels du soufisme le fondement d'une spiritualité qui n'a d'autre horizon que l'amour de $\mathrm{Dieu}^{8}$.

La proximité avec la période prophétique explique en partie que la vénération du Prophète, assurément bien présente, emprunte d'autres modalités ${ }^{9}$. L'une des rares exceptions est représentée par Hallāj exprimant son amour

4 Voir Orfali et Saab, Sufism, 222.

5 Orfali et Saab, Sufism, 223 .

6 Orfali et Saab, Sufism, 222.

7 Thibon, Les générations, $\mathrm{n}^{\circ}$ 12, $5^{\circ}$. Un peu plus tard et plus à l'est du monde musulman, il sera repris par Abū l-Ḥusayn al-Warrāq l'un des grands maîtres de Nishapur, mort avant 320/932 disant: "La marque de l'amour de Dieu c'est de se conformer (mutāba'a) à son bien-aimé", Thibon, Les générations, $\mathrm{n}^{\circ} 12,235$.

8 Le chapitre 35 de l'ouvrage mentionné précédemment, intitulé "Les fondements de leur école", réunit diverses citations de spirituels des trois premiers siècles qui, chacun à sa manière, énumère les principes fondamentaux du soufisme: le Prophète est quasiment absent, mis à part la référence à la sunna que nous avons évoquée, voir Orfali et Saab Sufism, 222-4. Sur cette question voir aussi, Radtke, "The eight rules of Junayd", 490-502.

9 Et son amour aussi, même si parfois cela apparaît de manière indirecte, par exemple Ḥătim al-Așamm (237/851-2) qui affirme : “[...] et celui qui prétend à l'amour du Prophète sans aimer la pauvreté est un imposteur"; Thibon, Les générations, ${ }^{\circ} 25,97$. 
du Prophète à travers son éloge ${ }^{10}$. Les choses vont évoluer qui vont donner au Prophète une plus grande centralité dans la vie spirituelle. Cela passa par des manifestations publiques, comme la mise en place des festivités du mawlid, mais surtout par l'émergence puis l'affirmation de la figure du maitre spirituel dont les contours vont s'affiner au fil des siècles pour finalement s'imposer aux alentours du ve $/ \mathrm{XI}^{\mathrm{e}}$ siècle ${ }^{11}$. Ce dernier occupe ainsi envers ses disciples une place similaire à celle du Prophète avec ses Compagnons, en tant que dépositaire de son héritage. Cela explique l'autorité quasi-absolue dont il jouit et l'attachement de plus en plus exclusif du disciple à sa personne. Il ne transmet pas seulement un savoir, fut-il celui de la vie intérieure, mais prend en charge la transformation progressive de ses disciples invités à suivre toutes ses directives. Ces nouvelles attributions conduisirent progressivement à une inflexion dans la conception de la voie spirituelle et même dans le rôle du shaykh. Les soufis, centrés au départ directement sur Dieu, ajoutèrent une étape supplémentaire dans la voie spirituelle, passant dorénavant par la médiation prophétique. Il serait sans doute intéressant de tenter de circonscrire plus en détails les raisons qui ont conduit à cette réorientation. Ce n'est pas ce qui nous occupera ici. J'ai choisi d'évoquer un ouvrage qui montre que la place occupée par le Prophète dans l'enseignement des maîtres soufis a considérablement évolué au point de devenir l'élément central, et même, pourrait-on dire, exclusif de celui-ci.

\section{L'ouvrage : son auteur et son maître}

Dans la littérature doctrinale du soufisme, le Kitāb al-ibrìz dont le titre complet est al-Dhahab al-ibriz min kalām Sayyidī al-Ghawth 'Abd al-Azīz al-Dabbāgh' ${ }^{12}$, est un ouvrage qui n'a pas d'équivalent. Il consigne les réponses du shaykh 'Abd al-Azīz b. Mas'ūd al-Dabbāgh, considéré comme un saint illettré $(u m m i ̄)^{13}$,

10 En particulier dans le recueil factice des Ṭawāsinn, et notamment le premier opuscule intitulé Țā Sìn al-azal, voir la traduction dans Massignon, La passion de Husayn Ibn Mansûr Hallâj, 300-3o6.

11 Sur cette question définie par Ibn 'Abbād al-Rundī comme le passage du shaykh al-ta tīm au shaykh al-tarbiya, qu'il date du V $\mathrm{e} / \mathrm{XI}$ siècle, voir Meier, "Khurāsān" in Meier, Essays, 189-219 et Meier, "Qusayrī's Tartīb al-Sulūk" 93-133. L'attribution de ce texte à Qushayrī a été remise en cause, voir Stern, "On the Authenticity of the Mystical Treatise Tartīb al-Sulūk” 65-95. Également, Thibon, L'ouvre d'Abū 'Abd al-Rahmmān al-Sulamī, 242-43.

12 Muḥammad 'Adnān al-Shammā̄e en a donné une excellente édition avec des annotations marginales qui en facilitent la consultation.

13 Sur le sens à donner à ce terme, voir O'Kane et Radtke, Pure Gold, 930. Sur ce type de sainteté, Chodkiewicz, "Le saint illettré" $§ 8$ et Geoffroy, Le soufisme en Égypte et en 
aux multiples questions que lui pose l'un des grands savants marocains de son temps, Abū l-Abbās, Aḥmad b. al-Mubārak al-Sijilmāsī al-Lamațī, né autour de 109o/1679 et mort en 1156/1743, qui s'est fait son disciple pour recueillir un savoir qu'il n'avait trouvé nulle part ailleurs ${ }^{14}$. Le cas de saints n'ayant pas suivi un enseignement de sciences religieuses n'est pas isolé, de nombreux exemples jalonnent l'histoire du soufisme ${ }^{15}$. De même le cas de savants ayant comme tuteur spirituel un illettré n'est pas unique : le grand soufi égyptien du seizième siècle 'Abd al-Wahhāb al-Sharrānī (m. 973/1565) eut pour maître 'Alī Khawwāṣ al-Burullusī (m. 939/ 1532), un tresseur de feuilles de palmier, considéré lui aussi comme $u m m \bar{l}^{16}$. Devançant Ibn al-Mubārak, Sha'rānī a également consigné dans deux opuscules les réponses de son maitre à ses questions ainsi que les consultations qu'il lui soumettait ${ }^{17}$.

Lampleur des questions abordées et la singularité des réponses apportées confèrent à cet ouvrage, commencé en 1129/1717 et achevé après la mort du maître, son caractère bien souvent énigmatique et singulier. Malgré une traduction partielle en français ${ }^{18}$, une traduction intégrale en anglais ${ }^{19}$ et une autre en turc ${ }^{20}$, cet ouvrage a été assez peu étudié. Avec toutefois une exception notable, le travail irremplaçable réalisé par B. Radtke qui a abordé cet ouvrage à travers quatre articles ${ }^{21}$. Selon lui, le Kitāb al-ibrizz est une sorte de bible des néo-soufis qui inspira des figures majeures des XVIII ${ }^{\mathrm{e}}$ et XIX ${ }^{\mathrm{e}}$ siècles, comme Aḥmad Tijānī (1737-1815), Aḥmad b. Idrīs22 (1749-50/1837) et ses disciples

Syrie, 299-307. L'appartenance de Dabbāgh à une famille de notables, nous allons le voir, conduit à s'interroger sur le sens à donner à ce terme dans son cas. Outre le fait que nous savons qu'il savait lire et écrire (O'Kane et Radtke, Pure Gold, n. 6, 116), il est assez peu probable qu'il n'ait suivi aucun cursus d'enseignement religieux.

14 Pas seulement car al-Lamați commente, parfois abondamment les propos de son maître, mais parfois livre également son propre exposé sur une question, comme par exemple dans le chapitre sept dont la section principale constitue un véritable traité de théologie dans lequel Dabbāgh ne joue aucun rôle, O'Kane et Radtke, Pure Gold, xviii.

15 Voir par exemple les noms mentionnés par Chodkiewicz, "Le saint illettré" § 9.

16 Sur lui Geoffroy, Le soufisme en Égypte et en Syrie, 304-7.

17 Sha'rānī, Durar al-ghawwāṣ et al-Jawāhir, ainsi que la notice qu'il lui consacre dans al-Ṭabaqāt al-kubrā, 150-69.

18 Zouanat, Paroles d'or.

19 L'ouvrage d'O'Kane et Radtke, déjà cité, représente un travail considérable de près d'un millier de pages. Par ailleurs, les éditeurs ont donné un aperçu très complet du contenu de l'ensemble des chapitres en introduction de leur traduction, O'Kane et Radtke, Pure Gold, 1-114.

20 Yildirim, el-Ibriz.

21 Radtke, "Ibrīziana" 113-58; "Der Ibrīz Lamațīs" 326-33; "Syrisch" 472-502; "Zwischen Traditionalismus und Intellektualismus" 240-67.

22 Radtke, "Aḥmad b. Idrīs". Il parle de deux voies muhammadiennes : l'une, classique est celle de l'imitation prophétique, tandis que l'autre (dont nous aurons à reparler avec 
Sanūsī (1787-1859), Muḥammad 'Uthmān al-Mīrghanī (1793-1852) et Ibrāhīm Rashīd (1813-74) ${ }^{23}$. C'est dire son importance pour la période contemporaine ${ }^{24}$.

Dès sa parution, ce livre parut inclassable aux yeux des contemporains, tel le chroniqueur Muhamammad al-Qādirī (m. 1187/1773) déclarant que son contenu «contredit les voies des soufis ${ }^{25}$ et recommandant de ne le mettre qu'entre les mains d'un public averti. Le même auteur rédigea une notice sur al-Lamațī dans laquelle il indique que ce dernier arriva dans la ville de Fès en 1110/ 1699170o. Il en deviendra l'une des autorités religieuses les plus respectées, donnant des cours à la Qarawiyyīn. Al-Qādirī suivit ses cours, l'écoutant lire et commenter plusieurs ouvrages, en particulier al-Shifă’ du Qāọī 'Iyāạ. Il mentionne également les maîtres d'al-Lamațī et cite les titres de quelques uns de ses ouvrages, dont aucun n'est a priori édité. Pour ce qui est du Kitāb al-ibriz, il indique que, selon lui, ceux qui l'ont désapprouvé sont plus nombreux que ceux qui l'ont défendu et que l'un de ses maîtres en a écrit une réfutation. Ce chroniqueur indique aussi que Lamațī fut enterré à côté de Dabbāgh, à Fès, dans le cimetière situé à l'extérieur de Bāb al-Futūh ${ }^{26}$.

Quant à son maître, son nom complet est Abū Fāris, 'Abd al-'Azīz b. Mas'ūd al-Dabbāgh al-Idrīsī al-Ḥasanī²7 (109o-1132/1679-1719) ${ }^{28}$. Son surnom ne renvoie pas à la profession de tanneur mais à une taxe dont sa famille aurait bénéficié de la part des tanneries de Salé, ville dont elle est originaire. Elle s'est ensuite installée à Fès au début du $\mathrm{IX}^{\mathrm{e}} / \mathrm{XV}^{\mathrm{e}}$ siècle et devint une famille de notables respectés ${ }^{29}$. La première rencontre de Ibn al-Mubārak avec son futur maître date de rajab 1125 (juillet-août 1713).

La description détaillée du contenu de ce livre proposée par J. O'Kane et B. Radtke nous dispense de reprendre ce point. Rappelons seulement que l'objet premier de l'ouvrage est de consigner les réponses que le shaykh Dabbāgh

Dabbāgh) vise à établir un contact direct avec le Prophète, considéré comme encore vivant et accessible.

23 Radtke, "Ibrīziana" 113-4. Il précise que Aḥmad b. Idrīs revendique une affiliation à la voie khaḍirī qui le rattache à la spiritualité de Dabbāgh, "Ibrīziana" 119.

24 Sur la réception de l'ouvrage, O'Kane et Radtke, Pure Gold, xxi-xxii.

25 Muhammad al-Qādirī, Nashr al-mathānī, vol. 3, 245-46 et O'Kane et Radtke, Pure Gold, xiv.

26 La traduction de cette notice est reproduite par les traducteurs, O'Kane et Radtke, Pure Gold, xi-xiii. Voir aussi Muḥammad al-Kattānī, Salwat al-anfās wa-muḥādathat al-akyās, vol. 2, 228-3o.

27 En plus des références déjà mentionnées, voir sa notice dans la Salwat al-anfās, vol. 2, 222-28. Voir également Vimercati Sanseverino, Fès et sainteté, 376-83. Et l'article de Pierre Lory, "al-Dabbāgh".

28 Kattānī hésite sur la date de sa mort et indique 1131 ou 1132, voir Salwat al-anfās, vol. 2, 228. Zouanat donne 1142/1720, il s'agit sans doute d'une erreur, Zouanat, Paroles d'or, 9.

O'Kane et Radtke, Pure Gold, xiv. 
apporte aux questions que lui pose al-Lamațī, et accessoirement des savants de son entourage. Toutefois, l'ouvrage ne se réduit pas à cela, car ce dernier, par ses commentaires et sa vaste érudition des questions religieuses, remet le plus souvent en perspective le savoir de son maître, exposant parfois le point de vue savant sur un sujet particulier, non d'ailleurs dans le but de briller en exhibant son savoir, mais au contraire en vue de montrer la supériorité du savoir inspiré de son maître. Cet ouvrage démontre de manière exemplaire qu'entre 'ulama $\bar{a}$ ' et awliy $\vec{a}$, entre les tenants d'une science livresque et les dépositaires d'une science inspirée, la confrontation et la concurrence ne sont pas les seules modalités régulant leur rapport ${ }^{30}$.

\subsection{L'itinéraire spirituel de Dabbāgh}

Le sujet que nous avons choisi de traiter, l'éducation spirituelle dans l'enseignement du shaykh Dabbāgh, nous impose comme préalable de mentionner quelques uns des événements qui balisèrent son propre itinéraire spirituel et influencèrent sa conception de la direction spirituelle. En résumant ce qu'il en dit lui-même, nous retiendrons les points suivants : au cours d'une première phase qui dura douze ans, il va d'un maître à l'autre ne rencontrant que désillusions et insatisfactions (entre 1109 et $1121 \mathrm{H}$.). Tout change lorsqu'il rencontre al-Khiḍr ${ }^{31}$ qui lui donne comme litanie quotidienne une invocation qu'il doit répéter sept mille fois et dans laquelle il demande à Dieu de le réunir avec le Prophète dans ce monde et dans l'au-delà ${ }^{32}$. Cet élément est doublement capital: dès lors Dabbāgh ne s'inscrit pas dans les lignages habituels du soufisme mais, initié par al-Khiḍr, il réactive un type de filiation amené à se développer par la suite ${ }^{33}$. Filiation qui justifie le qualificatif de $u m m \bar{\imath}$ pour indiquer que, comme al-Khiḍr, son savoir est d'inspiration divine ('ilm ladunnī, en référence à Cor. 18:65) et ne relève pas d'un apprentissage livresque. Ensuite, cette mise en présence du Prophète, recherchée par l'invocation expérimentée par Dabbāgh et clef de sa transformation, constitue par la suite l'axe central et l'aboutissement du cheminement spirituel, et par là même le critère suprême

$30 \quad$ Voir Chodkiewicz, "Le saint illettré" § 14-17.

31 Sur ce personnage voir la volumineuse étude de Franke, Begegnung mit Khidr.

32 Le texte de cette invocation est: "Allahuma yā rabbi bi-jāh sayyidinā Muhammad $b$. 'Abdallāh șallā Llāh 'alayhi wa-sallam ïma' baynì wa-bayna sayyidinā Muhammad $b$. 'Abdallāh fì l-dunyā qabl al-ākhira", (Mon Dieu, ô Seigneur, par considération envers notre maître Muhammad b. 'Abdallāh, que Dieu répande sur lui la grâce et la paix, réunis-moi à notre maître Muhammad b. 'Abdallāh dans ce monde-ci avant l'autre), Ibrīz, 1/52.

33 Cette filiation n'est pas nouvelle, elle a été revendiquée au moins par Ibn 'Arabī qui en plus d'une investiture directe par al-Khaḍir mentionne une autre affiliation à un maître ayant lui-même reçu la khirqa des mains d'al-Khaḍir, voir Addas, Ibn 'Arabī, 53 et pour le texte arabe, 36 . 
de la sainteté. En effet, trois ans plus tard (en 1125 H.), trois jours après le décès de 'Umar b. Muḥammad al-Hawwārī (m. 1125/1713), le gardien du sanctuaire de Sīdī 'Alī b. Hiirizhim ${ }^{34}$ auquel al-Khiḍr l'avait confié, il connaît l'illumination. Il décrit en détail cette expérience rarement mentionnée dans les sources ${ }^{35}$. La lumière y joue un rôle décisif, par la vision hors du commun qu'elle procure à Dabbāgh. Mais ce n'est pas la fin de son itinéraire qui se poursuit sous la conduite et les directives de 'Abdallāh al-Barnāwīi ${ }^{36}$ jusqu'au moment où il voit le Prophète en rêve. A ce moment-là, son dernier maître est rassuré sur le devenir de son disciple, car, si celui qui a vécu la première illumination est susceptible de retomber dans les ténèbres, il n'y a plus rien à craindre pour celui qui a connu « l'illumination dans la contemplation du Prophète ${ }^{37}$. Il n'a plus besoin de maitre et celui qui l'a conduit jusqu'au terme peut donc regagner son pays sans crainte pour le devenir spirituel de son disciple. Les étapes essentielles de cet itinéraire influenceront de manière décisive l'enseignement du maître.

\section{Présence prophétique et éducation du disciple}

Deux chapitres abordent plus particulièrement le sujet que nous avons choisi de traiter : le chapitre cinq qui porte sur la fonction de guide spirituel et l'aspiration du disciple à suivre une voie (irāda) et le chapitre six consacré au maître éducateur (shaykh al-tarbiya) ${ }^{38}$. Par la suite, nous nous intéressons plus particulièrement à la place dévolue au Prophète dans l'enseignement et l'éducation

34 Selon la prononciation berbère, pour d'autres vocalisations ; O'Kane et Radtke, Pure Gold, n. 56,129 .

35 Mubārak, Ibrīz, 1/51-5; Zouanta, Paroles d'or, 39-46 ; O'Kane et Radtke, Pure Gold, 128-34.

36 Sur lui, O'Fahey, Enigmatic Saint, 41. Il le mettra également à l'épreuve, par exemple en lui apparaissant sous les traits d'une belle femme qui tente de le séduire. Al-Barnāwī lui expliqua ensuite la raison d'une telle épreuve. Pour anecdotique qu'elle soit, la réponse n'en demeure pas moins révélatrice de données sociologiques: "du fait de ce que je connais de l'inclination des Chorfas pour les femmes ", et Dabbāgh faisait partie de ces Chorfas, ceux qui ont une ascendance prophétique comme son nom l'indique, Mubārak, Ibrīz, $1 / 56$.

37 Mubārak, Ibrīz, 1/55, ilā an yaqa'a lì l-fath fì mushāhadat al-Nabì ("jusqu'à ce que survienne en moi l'illumination dans la contemplation du Prophète"). La valeur de la préposition $f i$ est problématique : indique-t-elle la circonstance, la causalité, ou la concomitance? Zounat, Paroles d'or, 46 “jusqu'à ce que je connaisse l'illumination de la vision du Prophète" ; O'Kane et Radtke, Pure Gold, 133-34, "until I should experience the illumination of beholding the Prophet". Voir aussi Mubārak, Ibriz, 1/40o, où il est question de "contempler la station du Prophète" ou "d'arriver à la station du Prophète".

38 Mubārak, Ibrīz, 2/ 47-182 et O’Kane et Radtke, Pure Gold, 611-747. 
des disciples afin de comprendre comment se renouvelle la maîtrise spirituelle tout en restant inscrite dans la tradition du soufisme classique.

\subsection{Les directives spirituelles de Dabbāgh}

Une des premières questions posées au chapitre cinq est celle de la maitrise spirituelle. Elle n'est pas nouvelle car, d'après ce que rapporte Ibn al-Mubārak, Aḥmad Zarrūq (m. 899/1493) déclarait quà son époque l'initiation dans sa forme conventionnelle n'existait plus, car les imposteurs se sont multipliés et qu'il est devenu difficile de démêler le vrai du faux. Seule subsiste une initiation par l'énergie spirituelle (himma) et par l'état spirituel $(h \bar{a} l)^{39}$. Le shaykh Dabbāgh, modulant cette assertion, s'emploie à indiquer les caractéristiques du maître authentique. Trois éléments le caractérisent: le discernement spirituel (bașira), la maîtrise des passions humaines et être à l'abri des diverses formes d'illusion. Il résume en affirmant que le véritable éducateur (murabbī) est celui qui connaît les états spirituels du Prophète, celui qui a été abreuvé à sa lumière ${ }^{40}$. A celui-là on peut confier la conduite de l'esprit du disciple, car il est capable de l'élever jusqu'à l'amour du Prophète. Cette référence aux aḥwal $a l-n a b i ̄$ n'est pas originale. Sept siècles plus tôt Sulamī affirmait déjà dans ses Manāhij al-șüfiyya: "La première chose par laquelle l'aspirant commence, c'est d'imiter les états spirituels du Prophète $»^{41}$. Pour Dabbāgh, cette connaissance des états spirituels du Prophète est centrale et représente le point autour duquel s'articule tout l'enseignement de cette voie dabbäghiyya, dont on remarquera qu'elle n'est pas qualifiée de țarīqa muhammadiyya, expression que l'on ne trouve pas dans ce livre ${ }^{42}$.

\subsection{L'amour du maître}

Les deux chapitres consacrés à la relation du maître au disciple accordent une attention particulière à la nature du lien (rābița) qui unit l'un à l'autre ${ }^{43}$. Son importance est soulignée dans une phrase de Dabbāgh qui résume les étapes de la progression régissant le cheminement spirituel:

\section{Mubārak, Ibriž, 2/51 et sq; Pure Gold, 614 et sq.}

40 Mubārak, Ibrīz, 2/54.

41 Thibon, La voie des Hommes sincères, 43. Texte arabe édité par Kohlberg sous le titre Manāhiğ al-'ārifín, page 30 pour la citation. Sur cette question de l'ancienneté de la référence au Prophète dans le parcours spirituel, voir Chodkiewicz, "Le modèle prophétique" 201-26.

42 Radtke pense que son contenu permet de l'appliquer à la doctrine de Dabbāgh, mais cette appellation nous semble impropre, Radtke, "Ibrīziana" 123.

43 Radtke renvoie à l'étude de Meier qui a abordé la nature de ce lien chez les Naqshbandiyya, Radtke, "Ibrīziana" 123, n. 42. 
Nul ne peut aspirer (yatma ) à connaître Dieu sans connaître le Prophète et nul ne peut aspirer à connaître le Prophète sans connaître son maître et nul ne peut aspirer à connaître son maître sans avoir au préalable fait la prière des morts sur l'ensemble des humains (de l'humanité $)^{44}$.

Le renoncement au monde qui en constitue le point de départ n'est pas sans rappeler, par la radicalité de son expression, Abū Yazīd al-Bisțāmī (m. 261/875), le grand maître du Khurāsān, qui disait aussi avoir fait la prière mortuaire sur ce monde, mais il affirmait également: "J'ai connu Dieu par Dieu et j'ai connu tout le reste par la lumière de Dieu" 45 , perspective radicalement différente de celle de Dabbāgh comme nous le verrons par la suite. La lumière divine, qui agit directement chez Bisțāmī, est médiatisée pour Dabbāgh par la qualité de la foi de celui qui la transmet, le Prophète, puis le maître pour enfin toucher le disciple.

Quant à la connaissance du maître, elle repose très largement sur l'amour, selon Dabbāgh qui s'inscrit ainsi dans une tradition remontant aux premiers temps du soufisme qui le considérait déjà comme l'un des moteurs les plus efficaces du cheminement. Mais si l'amour de Dieu, voire du Prophète, était mis en avant comme nous l'avons vu, pour le cheikh Dabbāgh tout l'être du disciple doit prendre comme orientation, comme qibla, lêtre du maître afin de devenir le réceptacle de celui-ci qui alors le fécondera comme l'homme avec la femme. Il parviendra à l'extinction dans l'amour du maitre et le lien les unissant deviendra si fort et si exclusif ${ }^{46}$ que le disciple imitera, à distance, ce que fait son maître à tout instant, ni le temps ni l'espace n'étant susceptibles de les séparer. Voilà la condition pour prétendre à son héritage ${ }^{47}$. Toutefois Dabbāgh met en garde le disciple contre un amour vicié par des considérations mondaines : ce dernier ne doit pas l'aimer pour ce qu'il a, ses charismes, sa sainteté, sa science ou son secret, mais pour ce qu'il est ${ }^{48}$.

Aussi le maitre éprouve-t-il la sincérité du disciple en vue de l'amener à adhérer totalement et aveuglément à sa personne, quelles que soient les apparences sous lesquelles il se présente à lui. Cette absence de discernement de la

44 Et il poursuit: "Quand il ne se préoccupera plus d'eux dans ses paroles, dans ses actes et dans toutes ses affaires, alors lui viendra une miséricorde d'une manière qu'il n'avait absolument pas prévue", miséricorde qui désigne le Prophète, voir n. 67 et Mubārak, Ibrīz, 2/152. Et une version à peine différente, Mubārak, Ibrīz, 1/81.

Thibon, Les générations, $\mathrm{n}^{\circ} 18,81$.

46 Formulée sous forme de règle: "Lamour est sans partage (al-mahabba lā taqbal al-sharika)", Mubārak, Ibrīz, 2/76.

47 Mubārak, Ibrīz, 2/72-73.

48 Mubārak, Ibrīz, 2/75-76. 
part du disciple, caractéristique de l'amoureux envers l'aimé, qui le conduit à voir la perfection dans tout ce qui émane du maître est l'une des marques de l'amour et de l'engagement total du disciple, comme le sont également la vénération qu'il lui porte et l'adab dont il ne se départit point en sa présence ${ }^{49}$. Ces points ne sont pas nouveaux, les deux derniers par exemple étaient déjà énoncés quelques siècles plus tôt ${ }^{50}$, mais ils trouvent toute leur cohérence dans la place dévolue au Prophète, comme nous allons le voir.

Laction du maître sur son disciple est rendue possible par l'amour que celui-ci lui porte : il peut dès lors lui faire accomplir ce processus de purification intérieure destiné à chasser progressivement les ténèbres coulant dans les veines qui irriguent tout corps humain. Dabbāgh, par la plume d'Ibn al-Mubārak, identifie dix ténèbres qui affectent la nature argileuse de lêtre et que chaque homme doit surmonter pour se purifier avant d'accéder à la lumière ${ }^{51}$. Les deux dernières, les plus importantes donc, découlent, pour l'une, d'une méconnaissance, qualifiée de légère, envers la personne du Prophète mais aucun manquement envers lui ne peut être "léger"- et, pour l'autre, d'une ignorance avérée envers lui. Pour dissiper ces ténèbres intérieures, les exercices habituels de l'ascèse ne sont pas exclus, jeûne, retraite ou veille, mais ce qui compte le plus semble-t-il, l'essentiel, c'est l'amour absolu que le disciple doit apprendre à porter à son maître car il n'accédera à l'amour du Prophète qu'à travers lui. Toutefois, cet amour du maître ne doit pas être attaché à sa personne $\left(d h \bar{a} t^{52}\right)$, sinon il ne pourra profiter de lui qu'en sa présence. Au terme de ce processus, le disciple aboutira à la pureté du regard et à la plénitude de la lumière de la vision intérieure (șafā nażaruhu wa-tamma nūru bașīratihi $)^{53}$. Ce n'est qu'à la condition d'avoir expulsé de son être toute noirceur qu'il pourra accéder à la vision du Prophète.

49 Mubārak, Ibrīz, 2/77-78.

50 Par Sulamī par exemple, Thibon, L'ouvre, 240.

51 Mubārak, Ibrīz, 1/266-7o.

52 Précisons certains termes étudiés par Radtke, car le shaykh Dabbāgh fait un usage très fréquent en particulier de deux termes dhät et rūh qui ont chez lui une signification particulière : dhāt, c'est la nature humaine (bashariyya) qui comprend le corps, lâme et l'esprit, dans la perception sensible que l'on peut en avoir. Mais c'est aussi souvent l'aspect corporel et Dabbāgh parle ainsi de la nature argileuse, faite de terre (dhät turābiyya). Cette dhāt appartient à la partie sombre du monde (zalām). Un voile la sépare de l'esprit (rūhn), la partie la plus élevée de l'être humain qui relève elle de la lumière et détient les facultés humaines les plus élevées, l'intellection et la science. A la mort, l'esprit quitte le corps (dhāt) et rejoint le monde intermédiaire (barzākh), Radtke, "Ibrīziana" 119-27 et Zouanat, Paroles d'or, n. 3, 125 .

53 Mubārak, Ibrīz, 2/56. 


\subsection{Le Prophète}

Dans tout ce processus d'éducation, le Prophète occupe une position centrale. Rien de surprenant dans la mesure où cela ne fait que refléter la centralité cosmique du Prophète. Ce dernier est le secret de cette existence et toutes les créatures procèdent de lui, tirent leurs connaissances de la sienne et toutes sont créées de sa lumière ${ }^{54}$. Celle-ci est elle-même le produit des lumières des noms divins les plus beaux (al-asmäa al-ḥusnā $)^{55}$. La fonction de Muhammad est ainsi totalisante et occupe tout l'horizon du croyant, a fortiori du disciple. Aussi ce dernier doit par exemple avoir en permanence l'esprit occupé par le Prophète ou être absorbé par sa présence ${ }^{56}$. La conformité à la sunna du Prophète, l'orthopraxie, est ainsi déplacée d'une conformité à un texte ou à sa mise en pratique à une expérience vécue dans une forme de contact direct. Le shaykh Dabbāgh revendique d'ailleurs ce lien permanent avec le Prophète qui lui permet de l'interroger quand il ignore la réponse à une question ${ }^{57}$.

Dabbāgh conseille à ses disciples de se pencher fréquemment sur la vie du Prophète afin d'en connaître plus exactement les détails et d'en approfondir les diverses étapes, pour mieux se le représenter mentalement, car l'objectif est de rendre proche le Prophète et plus précise la représentation que le postulant s'en fait ${ }^{58}$. Mais ce n'est pas la seule raison. Car les détails du déroulement historique des événements n'importent que dans la mesure où ils conditionnent les arcanes de l'histoire sacrale de l'humanité, où ils participent à une meilleure compréhension de l'architecture invisible du monde dont il faut comprendre les ressorts pour en bénéficier. Ainsi, l'heure de réunion de l'assemblée des saints, le dīwān al-șāliḥin, est fixée au dernier tiers de la nuit, correspondant au moment de la naissance du Prophète. C'est pour la même raison que Dieu exauce les invocations dans ce laps de temps ${ }^{59}$. De même, le moment privilégié du vendredi, au cours duquel les demandes sont exaucées, est celui où le Prophète faisait le prêche sur sa chaire dans la mosquée de Médine ${ }^{60}$. Les effets de l'histoire prophétique ne sont donc pas limités à la période historique au cours de laquelle ils se déroulèrent mais continuent d'agir sur la marche

\footnotetext{
54 Mubārak, Ibrīz, 2/2o8-9.

55 Mubārak, Ibrīz, 2/187.

56 Mubārak, Ibrīz, 2/285.

57 Mubārak, Ibrīz, 1/13o.

$5^{8}$ Sulamī mentionnait déjà ce qu'il nommait un compagnonnage (șụba) avec le Prophète et même un comportement chevaleresque (futuwwa) envers lui, les deux termes paraissant d'ailleurs en grande partie interchangeable, signe d'une relation à cette présence prophétique toujours vivante voir, Sulamī, Adab al-ṣuḥba, 8 o et des référence plus complètes dans Thibon, L'ouvre, 369 .

59 Mubārak, Ibrīz, 2/18.

6o Mubārak, $I b r i ̄ z, ~ 2 / 18$ et 23-24.
} 
du monde. Non seulement ils sont en lien avec l'histoire de l'humanité, mais ils en constituent le principe organisateur. La lumière prophétique, source et origine du monde, demeure éternellement présente dans tous les éléments de la création ${ }^{61}$. L'importance du cycle solaire dans la cosmologie de Dabbāgh reflète cette omniprésence de la lumière qui est avant tout la lumière prophétique. D'où l'importance du chiffre 366 : c'est le nombre de formes différentes dans lesquelles peuvent se projeter les plus grands saints ${ }^{62}$; de même les sept lectures du Coran, liées selon Dabbāgh à sept dispositions de la nature prophétique comportent 366 aspects $(\text { wajh })^{63}$. Le corps humain lui aussi comprend 366 veines, chacune porteuse d'une spécificité, en général blâmable et que le disciple devra transformer en qualité64.

\subsection{La question de la foi}

Nous avons évoqué précédemment ce que Zarrūq avait appelé l'éducation par l'énergie (himma) et par l'état spirituel (hăl). Dabbāgh apporte des précisions essentielles pour notre propos, il explique:

La himma, celle du maître accompli, c'est la lumière de sa foi en Dieu. Par elle, il éduque et fait progresser son disciple. Si l'amour que le disciple porte à son maître provient de la lumière de la foi de ce dernier, alors il l'assiste qu'il soit présent ou non, même après sa mort et même après des milliers d'années. C'est pour cela que les saints, à chaque époque, recherchent l'assistance de la lumière de la foi du Prophète (nūr ìmān $a l-n a b \bar{l})$. Celle-ci les éduque et les fait progresser car leur amour pour lui est un amour pur et exclusif provenant de la lumière de leur foi ${ }^{65}$.

Nous avons dans cette citation un point d'articulation essentiel de l'hagiologie de Dabbāgh. La référence au nūr Muhammad, à la lumière muḥammadienne, trouve son fondement dans le texte coranique et a été abondamment reprise

61 Mubārak, Ibrīz, 2/54.

62 Mubārak, Ibrīz, 2/27.

63 Ce point est tiré de l'une des plus longues discussions de l'ouvrage, au chapitre 1, portant sur le hadìth qui traite des sept lectures du Coran, généralement compris comme les sept manières de le lire, mais qui sont reliées pour Dabbāgh à sept dispositions de la nature prophétique selon lesquelles le Coran fut révélé, O'Kane et Radtke, Pure Gold, xvii et 205-306, Mubārak, Ibrīz, 1/128-231. Ces sept dispositions correspondent par exemple au nombre de jour de la semaine; elles ont chacune une face tournée vers Dieu et une autre vers les hommes et représentent autant de lumières. Elles confèrent au Prophète une fonction de médiation sur tous les plans de l'existence, Mubārak, Ibriz, 1/13o.

64 Mubārak, Ibrīz, 2/54.

65 Mubārak, Ibrīz, 2/58. 
et commentée, pas seulement d'ailleurs par les représentants du soufisme ${ }^{66}$. La nouveauté dans l'expression résulte de l'adjonction du terme ìmān, la foi, comme origine ou vecteur de cette lumière. Qu'apporte l'insertion de ce terme dans l'expression précédente, alors qu'il représente l'un des plus riches du lexique coranique, aux définitions multiples et objet de débats parfois virulents entre les différentes écoles théologiques ${ }^{67}$ ? A ce qu'il semble, Dabbāgh n'a pas jugé utile de l'expliciter. La compréhension usuelle définit la foi comme l'adhésion à un ensemble de croyances et éventuellement une mise en œuvre de ce credo. Mais si ce terme ne s'inscrit pas chez Dabbāgh dans les débats théologiques, il lui est assigné un rôle capital dans l'accession à la sainteté ${ }^{68}$. Ce n'est pas sur les exercices spirituels, ou sur la réforme patiente et douloureuse des caractères que le cheikh met l'accent, même si bien sûr il ne les conteste ni ne les néglige, mais fondamentalement le premier élément, celui qui est indispensable pour que s'enclenche tout le reste, c'est la foi et celle-ci procède de la fonction prophétique. C'est cette foi, acte d'adhésion au message, totalement dépendante du Prophète en tant que transmetteur de la parole divine, qui est la source de tout bien, qui concentre toute l'attention. Ce n'est pas seulement une foi dans la vérité du message mais une adhésion à la personne de son transmetteur. La place spécifique reconnue à Abū Bakr, insurpassable même pour ceux qui ont connu la grande illumination, tient justement à la qualité de sa foi et à cette adhésion immédiate et sans réserve à la parole du Prophète comme à sa personne ${ }^{69}$. Cette adhésion, qui ne relève ni de la raison ni du recours à la tradition savante, est inscrite dans la nature la plus intime de l'individu ${ }^{70}$. Elle est l'expression ou le vecteur de la destinée humaine, le moyen pour que se réalise en particulier sa dimension eschatologique, et finalement elle procède de l'élection divine opérant la répartition entre les bienheureux et les damnés.

La conception de la foi que nous propose Dabbāgh pourrait paraître fort éloignée de celle soutenue par Ibn 'Arabī quand il affirme : « La science est une

66 Sur ce point et les diverses références, Chodkiewicz, Le Sceau des saints, 79-88.

67 L'expression apparaît à de nombreuses reprises dans le texte.

68 Il affirme par exemple : "Sans lui (le Prophète), notre foi en Dieu n'aurait aucune valeur, ni rien des bienfaits de ce monde ou de l'autre", Mubārak, Ibrīz, 1/270.

69 O'Kane et Radtke, Pure Gold, 537 et Ibriz, 1/456.

70 A rapprocher du terme qābiliyya, sur lequel Dabbāgh est interrogé, prédisposition à devenir aspirant, indispensable pour que se noue un lien entre un disciple et un maître. Elle comporte des degrés. Cette prédisposition pourrait paraitre une inclination naturelle vers la voie ou le maître, mais elle est avant tout une élection qui relève de la destinée de chacun. Elle est indispensable pour que se crée le lien (räbita $a$ ) entre le maître au disciple ; Mubārak, al-ibrïz, 2/61-2. 
des conditions de la sainteté ; la foi n'en est pas une condition $»^{71}$. Toutefois les mots ne doivent pas nous abuser. Dans un petit traité, Sulamī définit la foi comme "la science de la réalité divine" et aussi comme "la station de l'invisible $\gg^{72}$. Pour Dabbāgh, affirmant par ailleurs que les connaissances sont une des caractéristiques des saints, cette foi, qualité essentielle et qui s'applique également au Prophète, est bien comprise dans le sens où Sulamī l'entendait: une science des réalités divines, qui n'est certes pas celle des oulémas, et qui ouvre sur la contemplation de l'invisible. Plus largement, la vision de Dabbāgh débouche sur un autre débat: si la foi véhicule des connaissances intuitives qui sont fondamentales dans le parcours de l'aspirant, quelle place revient à l'apprentissage des sciences traditionnelles? Quelles sont les relations entre sciences inspirées et sciences traditionnelles transmises selon les voies habituelles de l'enseignement? Dabbāgh assurément se situe exclusivement dans le registre des premières, tandis que son disciple Ibn al-Mubārak tente dans cet ouvrage de dépasser ce clivage en démontrant que ces deux modalités, loin d'être incompatibles, sont au contraire convergentes et ne se contredisent point. Bien plus, il reconnaît la supériorité de la première sur la seconde. Quoi qu'il en soit, pour le shaykh Dabbāgh, la foi prime sur tout le reste; elle est la source ou le vecteur de la lumière prophétique et elle seule conditionne le devenir ultime du cheminant. Mais ce dernier a-t-il un moyen de la modifier par la discipline spirituelle? Même si l'amour semble à même d'infléchir ce cheminement, en dernier ressort, la foi, et la « qualité » de celle-ci, procède du décret divin et de ce que Dieu octroie à chaque être.

La citation qui a constitué le point de départ de ce débat nous offre une autre conclusion: de même que le Prophète continue d'être présent au monde et agissant au-delà de sa mort physique, de même le maître, qui en est l'héritier, continue à veiller sur ses disciples après avoir physiquement quitté ce monde. A condition toutefois que l'amour du disciple provienne de la lumière de la foi du maître. Dans ce cas, il pourra en profiter, présent ou absent, et même au-delà de la mort, car le maître l'assiste et le secourt par la lumière de la foi du Prophète donc il est le vecteur. C'est l'esprit $(r u ̄ h)$ de l'un et de l'autre, non leur enveloppe corporelle, qui perdure. Cela signifie qu'il n'est nul besoin pour le disciple de s'attacher à un autre maître au décès du premier, à condition toutefois que l'amour qu'il lui portait ait dépassé sa seule personne pour parvenir à l'amour de celui qu'il incarnait, le Prophète.

71 Cité par Chodkiewicz, "Le saint illettré dans l'hagiographie islamique" § 12. Voir Ibn 'Arabī, al-Futūhāt al-makkiyya, vol. 2, 5 2.

72 Ce traité est intitulé al-Farq bayna 'ilm al-sharīa wa-l-ḥaqĩqa ; Thibon, L'ouvre, 341. 


\subsection{Le secret (sirr)}

Un autre terme revêt une importance cruciale dans le lexique de Dabbāgh bien que son contenu précis, ici encore, ne soit pas explicité. Il s'agit du mot sirr, le secret. Quand Dabbāgh définit l'objectif de l'éducation spirituelle, il précise : « elle vise à amender la nature humaine et à la purifier de toutes ses exigences, afin qu'elle puisse porter le secret ${ }^{73}$. Cette définition, simple dans sa formulation, nous invite à parler d'éducation initiatique, dans la mesure où sa finalité réside dans la transmission d'un sirr, le seul but d'un maître étant de trouver le disciple susceptible de porter son sirr ${ }^{74}$. Dabbāgh brosse à grands traits les différentes phases de l'histoire de l'éducation initiatique (tarbiya) en islam, montrant par là qu'il a bien conscience de s'inscrire dans un processus historique évolutif: pour les trois premiers siècles, explique-t-il, les âmes, du fait de leurs qualités propres, n'avaient pas besoin d'intermédiaire pour se purifier, les hommes étant attaché à la quête de Dieu qui agissait directement en eux ; l'initiation spirituelle était donc inutile. Il suffisait au maître de chuchoter à l'oreille de son disciple et futur héritier pour lui transmettre son secret et provoquer l'illumination. Dans la phase suivante, l'attrait des plaisirs mondains corrompit les âmes et les maîtres imposèrent à leurs disciples la retraite, la remémoration de Dieu et la frugalité afin de rendre leurs âmes aptes à supporter le secret. Ensuite, la corruption gagna même les maîtres ou prétendus tels, les faussaires se multiplièrent à l'époque de Zarrūq l'obligeant, lui et ses semblables, à mettre en garde les aspirants et à les ramener vers « le Livre et la sunna ». Mais pour Dabbāgh, cela ne signifie nullement que la voie de l'initiation ait disparu, car la lumière prophétique demeurera à jamais ${ }^{75}$. Toutefois, le terme sirr, comme celui d'ìmān reste difficile à saisir ou plutôt est susceptible de plusieurs acceptions : soit il désigne l'héritage spirituel que le maître transmet au disciple qu'il investit comme son successeur, soit il désigne les connaissances suprasensibles auxquelles accède celui qui a connu l'illumination majeure. Enfin, dans un sens plus général, il désigne tout ce qui est voilé à une perception sensorielle ou n'est pas accessible de manière directe ${ }^{76}$. Mais le plus énigmatique reste que le Prophète est désigné comme «le secret de Dieu de cette existence ${ }^{77}$.

73 Mubārak, Ibrīz, 2/52. Dans le contexte qui est le nôtre, ce terme ne désigne pas la partie la plus secrète du cœur, parfois traduit, en reprenant la terminologie des mystiques chrétiens, par "la fine pointe de l'âme".

74 Mubārak, Ibrīz, 2/169.

75 Mubārak, Ibrīz, 2/52-4; Zouanat, Paroles d'or, 266-67 ; O'Kane et Radtke, Pure Gold, 614-15.

76 Sur ce dernier point Mubārak, Ibrīz, 2/186.

77 Mubārak, Ibrīz, 2/209. 
Un épisode important de la vie spirituelle de Dabbāgh est lié à ce terme sirr. Dans l'éducation des disciples, les récits édifiants (hikāyāt) que rapporte le maitre tiennent une place non-négligeable. Cela n'a rien de nouveau, elles font partie de l'arsenal éducatif employé depuis toujours dans la formation spirituelle qui se modèle d'ailleurs sur le discours coranique, particulièrement riche de ces récits et paraboles (mathal) propres à tout discours religieux. Mais Dabbāgh donne un fondement nouveau à ce mode d'enseignement en relatant son introduction dans l'assemblée des saints ${ }^{78}$. Lors de sa première participation, il lui fut rappelé la nécessité absolue de la discipline de l'arcane (kitmān al-sirr) et celui qui présidait cette assemblée ordonna à chacun de ses membres de conter une histoire illustrant ce sujet. Ils en racontèrent près de deux cents, précise Dabbāgh, ce qui suggère que même les saints complètent leur formation ou leur savoir par le biais de ces récits ${ }^{79}$. Si les maîtres utilisent ce langage, ils sont fondés à leur tour à en user avec leurs disciples pour les instruire. Dabbāgh ne s'en prive pas; au regard de la profusion des hikāyāt, présentes tout au long de l'ouvrage, il semble même que ce soit un moyen privilégié du shaykh pour illustrer son enseignement. Quant à ce qu'il convient de sceller, Dabbāgh reste muet sur ce point.

\subsection{L'attitude avec ses disciples}

Notons encore un point caractéristique de cette éducation: si depuis longtemps certains maîtres demandent à leur disciple de ne rien leur cacher de ce qui survient dans l'intimité de leurs pensées ou des épreuves qu'ils ont affrontées, il est plus rare que le maître s'impose la même franchise en retour envers ses disciples ${ }^{80}$. Dabbāgh explique que son silence sur ces points ne serait de sa part qu'une tromperie. Il érige en règle cardinale du compagnonnage spirituel (șhạba) que les deux parties ne dissimulent rien de leurs états intérieurs. Celui-ci n'établit donc pas de relation hiérarchique entre le maître et le disciple $^{81}$. D’ailleurs, pour Dabbāgh, ce n'est pas le disciple qui est redevable envers son maître mais bien l'inverse : si l'amour que le maître porte à ses disciples suffisait, alors tous parviendraient au terme de la voie, ce qui n'est pas le

78 Lassemblée des saints (Dīwān al-șālihīn) occupe tout le chapitre 4. Sur ce point, voir Chodkiewicz, Le Sceau des saints, 112-13.

79 Mubārak dit n'en avoir entendu que huit rapportées par son maître, Ibrīz, 1/59.

8o Mubārak, Ibrīz, 2/154.

81 Il demande à ses disciples de ne pas le considérer comme un shaykh mais comme un frère, car ils ne sont pas à même de s'acquitter des règles de convenance (adab) à avoir envers un shaykh, Mubārak, Ibrīz, 2/159. 
cas. Ce sont donc bien les qualités inhérentes au disciple et son amour pour le maître qui rendent possible l'action de ce dernier ${ }^{82}$.

\section{$3 \quad$ Les suprêmes étapes}

Après avoir présenté quelques uns des points essentiels de l'éducation spirituelle telle que le shaykh Dabbāgh la conçoit et la pratique, intéressons-nous maintenant à ce qui constitue la finalité et le terme de la voie.

\subsection{L'illumination}

L'illumination est une étape essentielle, pour ne pas dire la finalité principale de ceux qui suivent la voie ${ }^{83}$. Ce processus d'illumination ( fath) est complexe et le Prophète y joue là encore un rôle essentiel ${ }^{84}$. Il y a une illumination mineure et une autre qualifiée de majeure. Dabbāgh explique que le cheminant ayant reçu une illumination est confronté à de multiples dangers jusqu'à ce qu'il parvienne à la contemplation de la vision de la station du Prophète, il est alors assuré de la félicité, à l'abri des dangers ${ }^{85}$, car le Prophète est la seule créature à bénéficier d'une puissance d'attraction pour amener à Dieu et qu'il est la Miséricorde de Dieu ${ }^{86}$. Le disciple est ainsi assuré d'atteindre l'objectif ultime : la vision de Dieu ${ }^{87}$. La sainteté selon Dabbāgh se mesure à l'aune de la proximité avec le Prophète, ou plutôt à l'adéquation à la personne du Prophète. Ainsi, l'autorité suprême en ce monde, al-Ghawth, le Secours suprême, n'accède à ce statut qui fait de lui le primat de la hiérarchie spirituelle, que parce

\footnotetext{
$82 \quad$ Mubārak, Ibrīz, 2/77.

83 Cette question, qui est centrale dans tout l'ouvrage, est traitée dans l'introduction et dans le chapitre 9. Sur ce point voir aussi, Radtke, "Der Ibrīz" 33o.

84 Pour signaler la différence avec l'enseignement shādhilī, rappelons le conseil d'Ibn 'Ațāa' Allāh al-Iskandarī (m. 1309): "Si tu veux obtenir l'illumination (al-tanwīr wa-l-ishrāq), renonce à toute gouvernance (tadbir)", al-Tanwïrfi isqäț al-tadbìr, 115 .

85 Mubārak, Ibrïz, 2/277.

86 Mubārak, Ibrīz, 1/55. Expression que l'on trouve dans les paroles que son maître 'Abdallāh al-Barnāwī lui adresse avant de le quitter, après qu'il eut connu l'illumination suprême.

87 Dabbāgh distingue ensuite deux groupes : ceux qui s'anéantissent dans la contemplation de Dieu et un autre groupe, plus parfait, jouissant simultanément d'une double contemplation: leur esprit (arwāh ) s'anéantit dans la contemplation de Dieu tandis que leur être contingent (dhawāt) s'anéantit dans la contemplation du Prophète, qualifiée de plus agréable que d'entrer au Paradis ; Mubārak, Ibrīz, 2/286-87.
} 
qu'« aucun être $(d h \bar{a} t)$ n'a bu ${ }^{88}$ de l'être du Prophète autant que lui » 89 . De manière générale, Dabbāgh précise encore que celui à qui il sera donné de pouvoir le contempler devra auparavant avoir été abreuvé par les secrets de sa personne $(d h \bar{a} t)^{90}$. Ce langage figuré, volontairement abscons, ne fait pas référence à l'imitation du Prophète, à la mise en œuvre de la sunna, mais à une véritable identification à sa personne. Il renvoie également à un temps originel où tous les croyants, et pas seulement les musulmans, ainsi que les prophètes des communautés antérieures furent « arrosés » de la lumière prophétique en huit étapes successives, antérieures à leur création terrestre ${ }^{91}$. La différence entre les croyants vient de ce que chacun en a reçu. Selon une vision universaliste qui ne partage pas le monde entre musulmans et non-musulmans mais entre croyants et non croyants, la part muhammadienne de chaque homme détermine son appartenance à la communauté des croyants, quelle que soit la croyance, et son degré dans la hiérarchie spirituelle. L'action du Prophète dans ce monde et sur les hommes ne débute pas avec son apparition historique et la propagation de son message, mais participe de la destinée de chacun, selon le Décret divin, dès avant sa venue à l'existence.

\subsection{La vision du prophète}

Pour le shaykh Dabbāgh, le rêve occupe une place importante dans l'économie de la voie spirituelle ${ }^{92}$. L'une des marques de l'illumination mineure peut être la vision du Prophète en rêve. Celle-ci répond à une typologie ${ }^{93}$ : on peut voir son essence pure et noble ou seulement les multiples images de celle-ci; ses diverses manifestations sous le visage des autres prophètes ou des saints, ou encore, pour le disciple, sous la forme du maître. Leur interprétation, toujours

88 Dans un autre passage, il explique que c'est par la contemplation du Prophète que s'opère ce transfert décrit par la métaphore de l'absorption d'un liquide ; Mubārak, Ibrīz, 2/286. Le terme employé pour désigner cette opération est saqy, également utilisé pour "l'infusion" des noms divins; Mubārak, Ibrīz, 2/176-7. Radtke croît cette notion identique à celle de fayḍ chez les Tijāniyya ; Radtke, "Ibrīziana" 127.

89 Mubārak, Ibrīz, 2/301; O'Kane et Radtke, Pure Gold, 872. Non seulement ceux qui ont obtenu la grande illumination ne commettent plus de faute, mais les fautes antérieures qu'ils auraient pu commettre sont transformées en bonnes actions. Leur impeccabilité provient du fait que, contemplant Dieu en permanence, ils ne lui désobéissent plus, semblables en cela aux anges.

9o Mubārak, Ibrīz, 2/57.

91 Mubārak, Ibrīz, 2/191.

92 Katz, "Dreams", 270-84. Ce phénomène est très ancien. Katz a par exemple étudié les récits de 109 rêves rapportés dans un ouvrage de Muḥammad al-Zawāwī (m. 882/1477), Katz, Dreams, Sufism and Sainthood.

93 Mubārak, Ibriž, 1/279-82. 
ambivalente, dépend du parcours spirituel du rêveur. Dabbāgh donne des clefs d'interprétation, bien qu'il répugne à interpréter les rêves, car cela relève d'une science qui doit demeurer scellée ${ }^{94}$ : il s'agit presque à chaque fois d'une confrontation entre l'entité lumineuse du Prophète et la part de ténèbres qui demeure chez le rêveur. Cela oriente l'explication des circonstances dans lesquelles le Prophète apparaît. Seuls ceux qui ont obtenu l'illumination majeure (al-fath al-kabir) sont gratifiés de la vision du Prophète à l'état de veille. Cette possibilité de voir le Prophète à l'état de veille deviendra par la suite, selon Radtke, une caractéristique du soufisme tardif95.

Le plus souvent le veilleur voit la forme apparente du Prophète, non l'essence de son être ('ayn al-dhāt) qui se manifeste sous différentes représentations ou formes (șuwar) et peut être vue en rêve ou à l'état de veille, car La lumière du Prophète est partout. Il n'est pas un lieu qui soit dépourvu de sa lumière. C'est cette lumière qui fait apparaître sa forme comme le miroir révèle l'image de celui qui s'y regarde. Ainsi on peut le voir en même temps à l'est et à l'ouest, au nord ou au sud.

Ces divers éléments de l'enseignement spirituel de Dabbāgh : l'amour du maître, l'omniprésence du Prophète, l'illumination comme terme de la voie ou le caractère initiatique que manifeste cette importance attachée au sirr ne sont pas tous marqués du sceau de la nouveauté. Une étude des influences qui se sont exercées sur le maître de Fès ferait sans doute apparaître quelques personnages, comme Abū Ya'za, 'Abd al-Salam b. Mashīsh ${ }^{96}$ ou des lignages confrériques, en particulier les éléments shādhilis ${ }^{97}$. Mais il faudrait un travail approfondi pour mieux appréhender comment Dabbāgh a infléchi et modifié l'héritage de ses prédécesseurs.

\subsection{Quelques éléments de prophétologie}

Pour compléter ce rapide tableau, précisons encore la position de Dabbāgh sur la relation entre prophétie et sainteté. Muhammad est désigné dans le Coran comme un flambeau qui éclaire (Cor. 33, 46). Cette référence au nūr

\section{Mubārak, Ibrīz, 1/282.}

95 Radtke, "Ibrīziana", 122.

96 Les orientations de Dabbāgh présentent une corrélation forte avec sa célèbre prière, au contenu doctrinal particulièrement riche, commentée dans l'ouvrage, Mubārak, Ibrīz, 2/183-4. Sur cette prière, Zouanat, Ibn Mashīsh, 76-112. Sur Ibn Mashīsh, voir les travaux d'un colloque tenu à Tétouan en 2008, Sulamī et Saīì̄, éds., 'Abd al-Salām b. Mashīsh.

97 Les réponses que donnent Dabbāgh à un juriste qui l'interroge sur les voies de Shādhilī et de Ghazālī, sur leur méthode respective et sur celle qui a la précellence sur l'autre, ne laissent aucune ambiguïté sur celle qu'il juge supérieure, à savoir la première, même s'il reconnaît la validité de la seconde ; Mubārak, Ibrīz, 2/59-61. 
muhammadī fut pour les spirituels de l'islam une source de méditation permanente qui, par étapes, de Ja'far al-Ṣādiq et Sahl al-Tustarī, en passant par le Kitāb al-shifā bi-ta'rīf huquūq al-Muștafā du Qāḍī 'Iyāḍ (m. 544/1149), conduit avec Ibn 'Arabì à la doctrine de la Haqĩqa muhammadiyya $a^{98}$, puis à ses développements, en particulier dans le cadre de la confrérie shädhilī. Ce qui me semble nouveau avec Dabbāgh, c'est que le Prophète soit présenté comme porteur d'une triple lumière correspondant à la nature même des trois types de discours qu'il produit ${ }^{99}$ : le hadìth provient de la lumière établie dans sa nature humaine $(d h \bar{a} t)$, lumière qui ne se soustrait jamais à son regard, provenant elle-même des lumières divines, aussi inhérente à l'essence prophétique que la lumière solaire l'est au soleil en tant qu'astre. Quand les lumières divines se répandent et affectent cette nature, au point qu'il quitte son état habituel, il s'agit du Coran. Mais si ces lumières ne le font pas sortir de son état, alors il s'agit de paroles saintes (hadīth qudsī $)^{100}$ qui proviennent de l'esprit (rūḥ) du Prophète. Dans tous les cas, la parole prophétique est nécessairement accompagnée des lumières de la Vérité et tout ce qu'il dit procède d' une inspiration qu'il reçoit (waḩyun yūhāa $)^{101}$.

Ces précisions sont nécessaires pour appréhender les rapports entre prophétie et sainteté chez Dabbāgh. Ces derniers sont complexes et furent abordés par les premiers soufis. Ainsi Sulamī affirme dans ses Manāhij al-șādiqīn: « Les plus infimes demeures de la prophétie sont séparées des demeures les plus élevées de la sainteté »102 et il en donne la raison : les prophètes sont soutenus par une inspiration qui n'est affectée d'aucune illusion ni du moindre doute. Cette frontière nette entre prophétie et sainteté est soulignée à de nombreuses reprises par le cheikh Dabbāgh. Il affirme que le saint, quel que soit son degré, ne peut prétendre accéder au degré de connaissance du Prophète ${ }^{103}$. Un passage permet d'appréhender sa position ${ }^{104}$ :

Le bien qui émane du saint ne vient que de la baraka du Prophète car la foi, qui est la source de ce bien, ne lui est parvenue que par l'entremise (wāsița) du Prophète. La nature humaine (dhāt) du saint n'est pas

98 Comme l'a montré Chodkiewicz, Le Sceau des saints, 85. Voir aussi Addas, La Maison muhammadienne, 38 et sq.

99 Mubārak, Ibrīz, 1/286.

100 Mubārak, Ibrīz, 1/117-18.

101 En référence à Cor. 53:4.

102 Thibon, La voie des Hommes sincères, § 19 et texte arabe, 3 .

103 Mubārak, Ibrīz, 2/213.

104 De manière assez inexplicable Zouanat a omis ce passage capital alors qu'elle a traduit ce qui précède et ce qui suit, Zouanat, Paroles d'or, 281. 
différente de celle des autres hommes, contrairement aux prophètes car ils sont pétris d'impeccabilité et leur nature originelle ( fitra) les porte à la connaissance de Dieu et à la crainte si bien qu'ils n'ont nul besoin d'une loi à suivre, ni d'un enseignant dont ils tireraient profit car la Vérité qui habite leur être, - et c'est cela la caractéristique suprême de la prophétie selon laquelle ils ont été façonnés - les guide sur le chemin bien tracé et la voie droite ${ }^{105}$.

Si la notion d'impeccabilité n'a rien de nouveau dans la définition de la prophétie, déclarer que le Prophète, les prophètes, n'ont pas besoin de la loi, de par la nature fondamentale de leur être, paraît une affirmation audacieuse si on la rapproche de la lettre du verset dans lequel Dieu fait dire au Prophète : «Je ne suis qu'un homme semblable à vous, recevant une inspiration» (Cor. 18:110). Le verset coranique fait de l'inspiration divine la seule marque distinctive de la prophétie quand Dabbāgh en ajoute une autre: une dhāt, une nature qui est finalement différente de celle du commun de l'humanité. D'ailleurs, selon lui, il n'y a pas de voile entre le dhāt et le rūh chez le Prophète, contrairement aux autres humains. On entrevoit toutes les conséquences théologiques qui peuvent découler de cette position. Relevons aussi que l'indépendance à l'égard d'un múallim réduit à peu de choses le rôle de l'ange, chargé de transmettre la Parole divine.

La réponse que Dabbāgh donne à son disciple qui l'interroge sur les gharānīq ${ }^{106}$, démontre que ce maître ne tire pas seulement ses connaissances d'une inspiration, ou d'une vision intérieure (kashf). Il se montre aussi, dans certains cas, capable d'user d'un discours théologique ou du moins rationnel. Sur cette question, sa réponse est sans appel: les différentes traditions qui évoquent cette question sont pour lui sans fondement, car dans le cas contraire c'est tout l'édifice de la prophétie qui s'effondrerait ${ }^{107}$.

Sur de nombreux points, le shaykh Dabbāgh s'inscrit dans la tradition du soufisme même si sa prophétologie présente quelques aspects singuliers qui mériteraient d'être approfondis. Ses directives ne sont pas radicalement nouvelles, mais elles donnent une importance totalisante au Prophète qui perdura par la suite.

\footnotetext{
105 Mubārak, Ibrīz, 2/ 91.

106 En référence à un groupe de versets ou pseudo-versets de la sourate al-Najm ne figurant pas dans la recension 'uthmānienne en relation avec les déesses mecquoises et connus de nos jours sous l'appellation de "versets sataniques".

107 Mubārak, Ibrīz, 1/377.
} 
L'ouvrage de Ibn al-Mubārak ne prétend pas restituer l'enseignement de son maître Dabbāgh dans sa totalité. D'abord parce que son rédacteur apporte de nombreux compléments à l'enseignement qu'il consigne, le plus souvent pour rappeler la littérature savante qui s'y rapporte, et parfois pour pallier au silence du maître. Néanmoins, la matière même du livre en est pour l'essentiel les propos de son maître et en particulier les réponses aux questions qu'il pose, lui et parfois d'autres savants. Ensuite, parce que Ibn al-Mubārak a reformulé, par son travail d'écriture, un enseignement oral dont on peut supposer qu'il était en dialecte, langue absente de l'ouvrage. C'est donc l'enseignement de Dabbāgh que rapporte l'ouvrage mais à travers la compréhension qu'en eut son plus prestigieux disciple, Ibn al-Mubārak. Elément supplémentaire que ce dernier signale: tout ce que dit le maître ne s'écrit pas et certaines choses ne doivent pas être transmises, d'autres enfin ne le sont qu'oralement ${ }^{108}$. Ainsi malgré une fidélité qu'il n'y a aucune raison de récuser, ce que nous transmet Ibn al-Mubārak ne représente qu'une partie de l'enseignement qu'il reçut, renonçant, par choix ou sur ordre du maître, à transmettre la totalité de ce qu'il entendit de lui. Malgré ce que laisseraient croire les apparences, Ibn al-Mubārak n'est pas un simple transmetteur car il a mis en forme les propos de son maître et en a organisé l'agencement. Il est dès lors difficile de savoir avec précision ce qui est redevable à l'un ou à l'autre dans ce volumineux document.

Paradoxal, le livre l'est à plus d'un titre. Il l'est dans la confrontation entre une tradition savante, celle du rédacteur, et le discours inspiré d'un maître ayant accès à un monde invisible et insoupçonnable au commun des mortels. Le duo qu'ils forment n'est pas original et présente des modèles antérieurs. De même, le monde imaginal de Dabbāgh n'est pas totalement singulier, il n'est pas coupé de la tradition du soufisme, il s'y inscrit au contraire pleinement, croyons-nous, mais avec des particularités qui font tout son intérêt: le rôle du maître ou de la foi, la place du Prophète et son rôle totalisateur, la symphonie des lumières prophétiques qui transforme le saint en visionnaire inspiré, la nature des prophètes qui les distingue du commun des mortels. Ces divers points ne constituent que quelques uns des aspects les plus caractéristiques d'un maître dont l'originalité dépasse de beaucoup ces seuls éléments et qui ouvrit une voie nouvelle d'accès à la sainteté ne s'inscrivant pas dans le cadre des institutions confrériques, dans la mesure où il ne fonde pas une confrérie (țaríqa) mais une tradition spirituelle ${ }^{109}$. Son type spirituel n'est ni

108 Par exemple, Mubārak, Ibrīz, 1/398, 1/401 et 2/ 210.

109 Radtke, "Ibrīziana" 119. 
celui des saints-savants ni celui des saints-ravis (majdhūb) qui, plus ou moins, représentent les deux pôles entre lesquels s'inscrivent la plupart des saints en islam $^{110}$. Si les fous en Dieu ont représenté une forme d'alternative au légalisme desséché des docteurs de la loi ${ }^{111}$, Dabbāgh n'appartient en aucune manière à ce type de spirituel, il n'en a ni le discours, ni les apparences, ni le comportement. Et il n'appartient pas non plus à cette catégorie des savants du type de son disciple, Ibn al-Mubārak.

Dans le cadre d'une suspicion déjà ancienne envers la maîtrise spirituelle et ses dérives, exprimée par exemple par Zarrūq, Dabbāgh court-circuite, ni plus ni moins, les instances habituelles de la transmission et de l'éducation spirituelle. Il ne récuse pas la maîtrise spirituelle, la totalité de l'ouvrage démontrant de fait le contraire, mais en confiant, en dernier ressort, le devenir du disciple à sa capacité à tisser un lien direct avec le Prophète, il restreint le rôle des lignages spirituels et de leurs institutions. Finalement, il ramène la mâ̂trise à son fondement prophétique et réinstalle le Prophète comme présence vivante et transformante au centre d'une histoire universelle de la réalisation spirituelle. Servi par la plume d'Ibn al-Mubārak, il installe la figure du visionnaire, au sens premier du terme, comme un modèle de sainteté supplémentaire et alternatif aux carences du temps et des institutions soufies. Mais ce projet est-il bien celui du maître Dabbāgh ou est-ce celui de son disciple, Ibn al-Mubārak ? Car, comme nous l'avons souligné, il est finalement très difficile d'apprécier son rôle exact dans la formulation de cette somme. Ce dernier, nous l'avons vu, complète le discours de son maître, le conforte par ses références savantes, le cautionne finalement de bout en bout. Ce faisant, n'est-ce pas lui qui impose la voie de son maître comme une alternative possible pour sortir le soufisme des innombrables critiques auxquelles il est confronté depuis plusieurs siècles? Ne fallait-il pas sa caution savante pour que cette voix fasse émerger une voie? L'ouvrage ne propose pas de réponse explicite à ce type de question. Les nouvelles voies qui, aux siècles suivants, s'inspirèrent de cet enseignement démontrent l'efficacité de ces nouvelles orientations, qui, à défaut de faire taire la critique, ont puissamment contribué au renouvellement doctrinal du soufisme. Toutefois, il reste encore beaucoup à faire pour prolonger les travaux engagés par Radtke et mieux appréhender l'impact d'al-Ibrīz sur les auteurs soufis postérieurs.

110 Dabbāgh explique la différence entre le cheminant (sālik) et le ravi-extatique (majdhūb), Mubārak, Ibrīz, 2/34-36.

111 Sur le majdhūb comme figure de sainteté alternative, Amri, Croire au Maghreb médiéval, en particulier 85-193. 


\section{Bibliographie}

\section{Sources}

Aḥmad b. al-Mubārak. Al-Dhahab al-ibrīz min kalām Sayyid̄̄ al-Ghawth 'Abd al-'Azīz al-Dabbāgh, éd. Muhammad 'Adnān Shammāc, Damascus, s. n. 1404/1984-1406/1986.

Ibn 'Ațā̄ Allāh. al-Tanwīr fì isqāṭ al-tadbīr, éd. Mūsā Muḥammad 'Alī al-Mūshī et 'Abd al-'Āl Aḥmad al-'Arabī, Cairo, Maṭba'a al-Qāhira al-ḥadītha, 1971.

Ibn 'Arabī. al-Futūḥāt al-Makkiyya, Beirut, Dār Ṣādir, 1990.

Ibn 'Arabī. Le livre de la filiation spirituelle, texte arabe établi, traduit et présenté par C. Addas, Marrakech, Al Qubba Zarqua, 2000.

Kattānī, M. b. J. Salwat al-anfās wa-muhādathat al-akyās, éd. 'Abdallāh al-Kattān̄̄ et alii, Casablanca, Dār al-thaqāfa, 2004.

Qushayrī, A. l-Q. al-Risāla al-qushayriyya, éd. 'Abd al-Ḥalīm Maḥmūd et Mạ̣mūd Ibn al-Sharīf, Cairo, Dār al-kutub al-ḥadītha, 1966, rééd. 1972.

O'Kane, J., et Radtke, B. Pure Gold from the Words of Sayyidī 'Abd al-Azìz al-Dabbà $\dot{g}$. (Al-Dhahab al-Ibrīz min Kalām Sayyidī 'Abd al-'Azīz al-Dabbāğ), Leiden, Brill, 2007.

Orfali, B. and Saab, N. Sufism, Black and White: A Critical Edition of Kitāb al-Bayāạ wa-l-Sawād by Abū l-Hasan al-Sirjānī (d. ca. 470/1077), Leiden, Brill, 2012.

Qādirī, M. b. al-Ṭ. Nashr al-mathānī li-ahl al-qarn al-ḥādī 'ashar wa-l-thānī, éd. Muḥammad Ḥajjī et Aḥmad Tawfīq, Rabat, Maktabat al-țālib, 1977-86.

Sha'rānī, 'A. al-W. Durar al-ghawwāṣ 'alā fatāwā sayyid̄̄ 'Alī al-Khawwāạs, Cairo, al-Maktaba al-azhariyya li-l-turāth, 1418/1998.

Sha'rānī, 'A. al-W. al-Jawāhir wa-l-durar, Cairo, al-Maktaba al-azhariyya li-l-turāth, 1418/1998

Sha'rānī, 'A. al-W. al-Ṭabaqāt al-kubrā, Beirut, Dār al-fikr, n.d.

Sulamī, A. 'A. al-R. Manāhij al-'ārifiñ, in E. Kohlberg, ed. JSAI, 1 (1979), 19-39 ; bibliographie, 2 (1980) 384-5.

Sulamī, A. 'A. al-R. Ādāb al-șuḥba wa-ḥusn al-'ishra, in M. J. Kister, ed. Oriental notes and studies, Jerusalem, The Israel Oriental Society, 1954.

\section{Études}

Addas, C. La Maison muhammadienne. Aperçus de la dévotion au Prophète en mystique musulmane, Paris, Gallimard, 2015.

Amri, N. Croire au Maghreb médiéval. La sainteté en question XIV ${ }^{e}-X V^{e}$ siècle, Paris, Cerf, 2019.

Chodkiewicz, M. "Le saint illettré dans l'hagiographie islamique", Les Cahiers du Centre de Recherches Historiques, 9 (1992), en ligne https ://doi.org/10.400o/ccrh.2799.

Chodkiewicz, M. "Le modèle prophétique de la sainteté en Islam", Al-Masāq :Journal of the Medieval Mediterranean, 7 (1994), 201-226. 
Franke, P. Begegnung mit Khidr: Quellenstudien zum Imaginären im traditionellen Islam, Beiruter Texte und Studien 79, Stuttgart, Steiner, 2000.

Geoffroy, E. Le soufisme en Égypte et en Syrie sous les derniers Mamelouks et les premiers Ottomans. Orientations spirituelles et enjeux culturels, Damascus Ifpo, 1995.

Katz, J. "Dreams in the manāqib of a Moroccan Sufi shaykh. 'Abd al-'Azīz al-Dabbāgh (d. 1131/1719)" in L. Marlow, ed. Dreaming across boundaries. The interpretation of dreams in Islamic lands, Cambridge, MA, Harvard University Press, 2008.

Katz J. Dreams, Sufism and Sainthood, Leiden, Brill, 1996.

Lory, P. "al-Dabbāgh, 'Abd al-'Azīz", in K. Fleet, G. Krämer, et al., eds. Encyclopaedia of Islam, Third Edition, Consulted online 27 June 2019, First published online : 2011.

Massignon, L. La passion de Husayn Ibn Mansûr Hallâj, Paris, Gallimard, 1975.

Meier, F. "Hurāsān und das Ende der klassischen Sufik" in Atti del Convegno Internazionale sul tema : La Persia nel Medioevo (Roma 3 marzo-5 aprile), Rome, Academia dei Lincei, 1971, 545-70 ; repris sous le titre « Khurāsān and the End of Classical Sufism » in F. Meier, Essays on Islamic Piety and Mysticism, trad. par J. O'Kane avec l'assistance éditoriale de B. Radke, Leiden, Brill, 1999, 189-219.

Meier, F. “Qušayrī’s Tartīb al-Sulūk” in F. Meier, Essays on Islamic Piety and Mysticism, trad. ang. par John O'Kane avec l'assistance éditoriale de B. Radke, Leiden, Brill, 1999, 93-133.

O'Fahey, R. S. Enigmatic Saint : Ahmad Ibn Idris and the Idrisi tradition, London, Hurst, 1990.

Radtke, B. "The eight rules of Junayd: a general overview of the genesis and development of Islamic Dervish orders" in T. Lawson, ed. Reason and Inspiration in Islam: Theology, Philosophy and Mysticism in Muslim Thought. Essays in Honour of Hermann Landolt, London, I.B. Tauris, in association with The Institute of Ismaili Studies, 2005.

Radtke, B. "Ibrīziana: Themes and Sources of a Seminal Sufi Work", Sudanic Africa 7 (1996), 113-58.

Radtke, B. "Der Ibrīz Lamațīs" in XXvi, Deutscher Orientalistentag. Annaherung an das Fremde, Stuttgart, 1998, 326-33.

Radtke, B. "Syrisch : Die sprache der engel, der geister und der erleuchteten. Einige stücke aus dem Ibrīz des Aḥmad b. al-Mubārak al-Lamațī, Jerusalem Studies of Arabic and Islam 32 (2006), 472-502.

Radtke, B. "Zwischen Traditionalismus und Intellektualismus: Geistesgeschichtliche und historiographische Bemerkungen zum Ibrīz des Aḥmad b. Mubārak al- Lamaṭ̄̄, in E. Wardini, ed. Built on Solid Rock, Studies in Honour of Professor Ebbe Egede Knudsen on the Occasion of his 65th Birthday April 11 1997, Oslo 1997, Nuvus Forlag, 240-67.

Radtke, B. "Aḥmad b. Idrīs", in K. Fleet, G. Krämer, et al., eds. Encyclopaedia of Islam, Third Edition, Consulted online on 21 January 2019, First published online 2012. 
Sulamī, J., et al-Sa'īdī, A., eds. 'Abd al-Salām b. Mashīsh wa-l-țarīqa al-shādhiliyya min al-qarn al-sābic ilā l-qarn al-tāsi` al-hijrī, Tétouan, Manshūrāt jamiiyyat Titțāwin Asmīr, 1438/2016.

Stern, E. "On the Authenticity of the Mystical Treatise Tartīb al-Sulūk ascribed to Al-Qushayrī", Studia Islamica, 107/1 (2012), 65-95.

Thibon, J-J. Les générations des Soufis, Leiden, Brill, 2019.

Thibon, J-J. L'ouvre d'A bū 'Abd al-Raḥmān al-Sulamī (325/937-412/1021) et la formation du soufisme, Damascus, Ifpo, 2009.

Thibon, J-J. “La voie des Hommes sincères parmi les Soufis”, introd. et trad. du texte de Sulamī, Manāhij al-ṣādiqīn in La règle d'Abraham, ${ }^{\circ}$ 34, Milan, Archè, 2012, 27-64.

Vimercati Sanseverino, R. Fès et sainteté, de la fondation à l'avènement du Protectorat (808-1912), Rabat, Centre Jacques Berque, 2014.

Yildirim, C. el-Ibriz Şeriat-Tarikat Marifet-Hakikat eş-şeyh Abdülaziz Debbağ hazretleri, Istanbul, Demir Kitabevi, 1979.

Zouanat, Z. Paroles d'or, Paris, Éditions du Relié, 2001.

Zouanat, Z. Ibn Mashīsh Maître d'al-Shādhilī, Casablanca, Najah el-jadida, 1998. 